\title{
Staphylococcus aureus Bacteremia in Children of Rural Areas of The Gambia, 2008-2015
}

\author{
Aderonke Odutola, Christian Bottomley, Syed A. Zaman, Jodi Lindsay, Muhammed Shah, \\ Ilias Hossain, Malick Ndiaye, Chidebere D.I. Osuorah, Yekini Olatunji, Henry Badji, \\ Usman N.A. Ikumapayi, Ahmad Manjang, Rasheed Salaudeen, Lamin Ceesay, Momodou Jasseh, \\ Richard A. Adegbola, Tumani Corrah, Philip C. Hill, Brian M. Greenwood, Grant A. Mackenzie
}

\begin{abstract}
Staphylococcus aureus bacteremia is a substantial cause of childhood disease and death, but few studies have described its epidemiology in developing countries. Using a population-based surveillance system for pneumonia, sepsis, and meningitis, we estimated $S$. aureus bacteremia incidence and the case-fatality ratio in children $<5$ years of age in 2 regions in the eastern part of The Gambia during 20082015. Among 33,060 children with suspected pneumonia, sepsis, or meningitis, we performed blood culture for 27,851 ; of 1,130 patients with bacteremia, $198(17.5 \%)$ were positive for $S$. aureus. S. aureus bacteremia incidence was 78 (95\% $\mathrm{Cl} 67-91$ ) cases $/ 100,000$ person-years in children $<5$ years of age and 2,080 (95\% Cl 1,621-2,627) cases/100,000 person-years in neonates. Incidence did not change after introduction of the pneumococcal conjugate vaccine. The casefatality ratio was $14.1 \%(95 \% \mathrm{Cl} 9.6 \%-19.8 \%)$. Interventions are needed to reduce the $S$. aureus bacteremia burden in The Gambia, particularly among neonates.
\end{abstract}

$\mathrm{I}$ n 2016, invasive bacterial diseases accounted for one quarter of the 5.6 million childhood deaths worldwide (1). Most invasive bacterial diseases occur in sub-Saharan Africa and other low- and middle-income countries (2). Deaths caused by these diseases outnumber those caused

Author affiliations: London School of Hygiene and Tropical Medicine, London, UK (A. Odutola, C. Bottomley, S.A. Zaman, B.M. Greenwood, G.A. Mackenzie); Medical Research Council Unit The Gambia at the London School of Hygiene and Tropical Medicine, Banjul, The Gambia (A. Odutola, S.A. Zaman, M. Shah, I. Hossain, M. Ndiaye, C.D.I. Osuorah, Y. Olatunji, H. Badji,

U.N.A. Ikumapayi, A. Manjang, R. Salaudeen, M. Jasseh,

R.A. Adegbola, T. Corrah, G.A. Mackenzie); St. George's

University of London, London (J. Lindsay); King Fahad Medical City, Riyadh, Saudi Arabia (A. Manjang); Ministry of Health and Social Welfare, Banjul (L. Ceesay); University of Otago, Dunedin, New Zealand (P.C. Hill); Murdoch Children's Research Institute, Parkville, Victoria, Australia (G.A. Mackenzie)

DOI: https://doi.org/10.3201/eid2504.180935 by malaria among children $<5$ years of age (3). The main bacteria implicated in invasive bacterial diseases has been Streptococcus pneumoniae and Haemophilus influenzae (4). However, after the widespread use of conjugate vaccines against $H$. influenzae type b (Hib) and S. pneumoniae, Hib disease has decreased considerably (5), and vaccine-serotype pneumococcal disease is declining (6). The decreased disease incidence associated with these pathogens has led to Staphylococcus aureus becoming a relatively more common cause of invasive bacterial disease (7). The clinical spectrum of $S$. aureus disease ranges from life-threatening invasive diseases, such as septicemia, pneumonia, osteomyelitis, endocarditis, meningitis, and brain abscess, to less severe skin and soft tissue infections. S. aureus bacteremia is often used as a marker of invasive $S$. aureus disease (8).

In high-income countries, $S$. aureus bacteremia is the second most common cause of neonatal sepsis, after group B Streptococcus (9). From the 1970s through the 2000s, the incidence of $S$. aureus bacteremia among children $<16$ years of age increased in several countries (10), probably because of the increased use of central venous catheters and other factors (10). In the 2010s, the incidence of $S$. aureus bacteremia remained stable (11) or decreased (10).

In Africa, $S$. aureus bacteremia is a common cause of invasive bacterial disease in children. Before the introduction of the Hib vaccine and pneumococcal conjugate vaccine (PCV), population-based studies in Kenya and Mozambique showed that $S$. aureus was the most common gram-positive pathogen among neonates with sepsis $(4,12)$. Also, hospital-based studies showed $S$. aureus to be the most common cause of invasive bacterial disease in children $<3$ months of age in The Gambia (13) and one of the main causes of invasive bacterial disease in children $<5$ years of age in Nigeria (14).

Few population-based studies have been conducted in sub-Saharan Africa on the incidence of $S$. aureus bacteremia. In South Africa, a population-based study of children $<13$ years of age in an area with a high HIV prevalence 
indicated an incidence of 26 cases/100,000 person-years (15). A study in Kenya involving children admitted to a secondary healthcare facility showed an incidence of 27 cases/100,000 person-years in children $<5$ years of age; the highest incidence was in infants ( 89 cases/100,000 personyears) (4). However, variation in the age groups studied and methods used preclude direct comparison of these studies $(4,12,13,15)$. After introduction of the Hib vaccine and before the introduction of PCV, a hospital-based study in The Gambia reported that $S$. aureus was the most common cause of bacteremia (16).

Given the paucity of population-based data on the epidemiology of $S$. aureus bacteremia in sub-Saharan Africa, we studied the incidence, clinical characteristics, casefatality rate, and risk factors for $S$. aureus bacteremia in young children in a rural region of The Gambia. We also explored the association of $S$. aureus bacteremia with the introduction of PCV.

\section{Methods}

\section{Study Site and Population}

Surveillance for septicemia, pneumonia, and meningitis was performed among children $\geq 2$ months of age residing in Basse in the Upper River Region of The Gambia through the Basse Health and Demographic Surveillance System (BHDSS) (Figure 1). We established the BHDSS in 2007, and the population in this surveillance area $(\approx 179,000$ persons in $2015,19 \%<5$ years of age) is enumerated every 4 months. The BHDSS is served by 5 satellite clinics and the Basse Health Centre (Basse, The Gambia), a primary and secondary healthcare facility with 25 beds to care for children. During 2011-2015, surveillance was extended to include all residents $<5$ years of age, and a similar surveillance was set up in the adjacent district of Fuladu West for all residents $<5$ years of age during a similar time range (2012 2014) through the Fuladu West Health and Demographic Surveillance System (FWHDSS; Figure 1). The population in Fuladu West is enumerated annually (population 92,464 in $2014,18 \%<5$ years of age). The FWHDSS is served by Bansang Hospital (Bansang, The Gambia) and 2 satellite clinics. Every resident in the areas surveilled by the BHDSS and FWHDSS was assigned a unique identifier.

The conjugate vaccine for Hib was introduced into the Gambian National Programme on Immunization in 1997, and the vaccine for pneumococcus was introduced in 2009. The 7-valent PCV (PCV7) was replaced by the 13-valent vaccine (PCV13) in 2011. In 2012, vaccine coverage for the third dose of the diphtheria-pertussis-tetanus vaccine in these regions surveilled was $81.7 \%$ (17). In The Gambia, transmission of Plasmodium falciparum is largely restricted to the short rainy season during July-November (18).

\section{Surveillance Procedures}

During May 12, 2008-December 31, 2015, nurses screened all children 2-59 months of age who arrived at a health center participating in the surveillance and who had a unique identifier for septicemia, pneumonia, and meningitis, according to standardized criteria (also referred to as referral surveillance) (19). Children who were admitted and children who were treated as outpatients were screened. Children who screened positive were referred to clinicians who used standardized criteria for assessment and investigation (19). Data collected included age, sex, anthropometric measurements, signs and symptoms, and suspected diagnosis. Blood was collected for culturing, and depending on clinical presentation, cerebrospinal fluid, lung aspirate, or pleural fluid samples were have also been collected for conventional microbiological

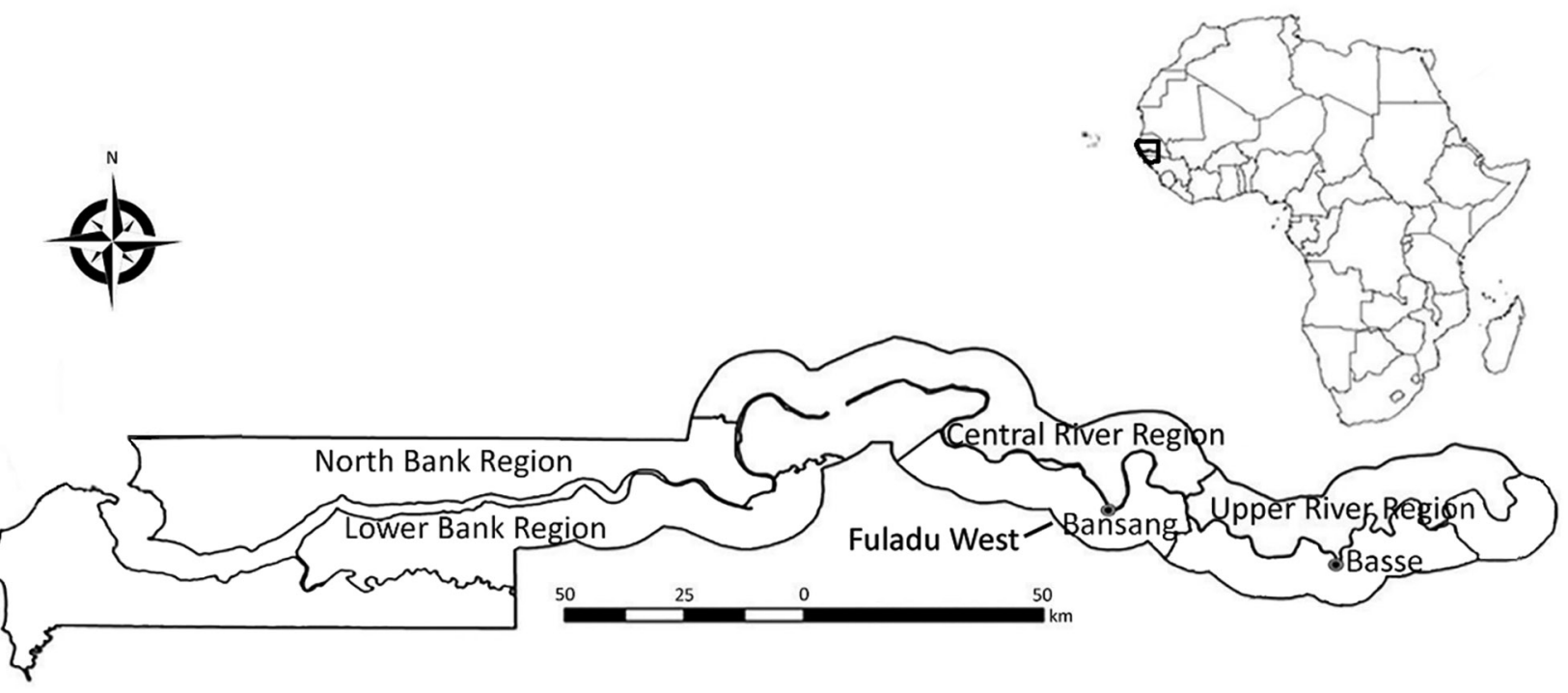

Figure 1. Regions surveilled for Staphylococcus aureus bacteremia among children $<5$ years of age through the Basse and Fuladu West Health and Demographic Surveillance Systems, The Gambia, 2008-2015. Inset indicates location of The Gambia in Africa. 
tests (6). Rapid diagnostic tests for malaria (ICT Malaria P.f. Antigen; ICT Diagnostics, http://www.ictdiagnostics.co.za) were routinely performed during the rainy season and at other times at the discretion of the clinician.

During March 1, 2011-December 31, 2015, surveillance was expanded in the BHDSS to include all children 0-59 months of age who were admitted with an acute medical problem from whom a blood sample was collected for culture (also referred to as admission surveillance). During September 12, 2011-December 31, 2014, a similar admission surveillance was conducted for children 0-59 months of age admitted with an acute medical problem using the FWHDSS. All S. aureus bacteremia cases were linked to the Health and Demographic Surveillance System databases by using the unique identifier.

\section{Laboratory Methods}

We collected 1-3-mL blood samples from all patients with suspected septicemia, pneumonia, or meningitis; inoculated blood samples into BACTEC bottles (Becton Dickinson, https://www.bd.com); and incubated them in an automated BACTEC 9050 Blood Culture System (Becton Dickinson) for a maximum of 5 days. We subcultured positive cultures on blood agar plates and confirmed isolates as $S$. aureus by using catalase and coagulase tests. We classified cultures that grew Bacillus spp., Corynebacterium spp., and coagulase-negative Staphylococcus as contaminated. We used standard methods to investigate other body fluid samples collected for microbiological tests (20). We used disc diffusion methods to determine antimicrobial drug susceptibility according to the Clinical and Laboratory Standards Institute guidelines (21). We categorized all S. aureus isolates resistant to cefoxitin as methicillin-resistant.

We defined $S$. aureus bacteremia cases as clinically suspected cases of septicemia, pneumonia, meningitis, osteomyelitis, septic arthritis, pyomyositis, or abscess identified by using standardized criteria (19) in patients from whom $S$. aureus was isolated from their blood.

\section{Statistical Methods}

We used referral and admission surveillance data for statistical analyses. The unique identifier assigned to every patient enabled us to avoid duplication of data in our data set. We used the referral surveillance data to investigate trends in incidence because these data covered a longer period (2008-2015) than the admissions surveillance data (2011-2015). We used both the admission and referral surveillance data to estimate age-specific incidence and the case-fatality ratio (CFR).

We obtained incidence estimates by dividing the number of $S$. aureus bacteremia cases by the number of person-years at risk using the estimated midyear population. To account for the shorter period of observation in 2008 (May 12-
December 31), we calculated person-years at risk as the midyear population multiplied by $234 / 365$. We calculated incidence in neonates using 2 methods, first as cases per 1,000 live births and second as cases per 100,000 person-years. We defined the neonatal period as the time from birth to 28 days of age.

With the referral surveillance data, we assessed trends in incidence over time and variation in incidence before (pre-PCV period, May 12, 2008-May 11, 2010) and after (PCV13 period, January 1, 2013-December 31, 2015) the introduction of PCV7 using Poisson regression with robust error variance to allow for overdispersion. To account for the increased rate of eligible patients requiring blood culture over time, we adjusted the number of $S$. aureus bacteremia cases of each age group and year by multiplying by the ratio of the annual rate of eligible children enrolled over the mean rate of eligible children enrolled during the entire study period (6). For the denominators of the pre-PCV and PCV13 periods, we used the average of the corresponding midyear populations indicated by the BHDSS.

We defined CFR as the number of patients with $S$. aureus bacteremia who died before discharge divided by the total number of patients with $S$. aureus bacteremia. We identified potential risk factors for death before discharge using logistic regression, although surveillance was not designed to assess risk factors. We generated weight-for-age and weight-for-height z-scores using the 2006 World Health Organization child growth standards (https://www.who.int/ childgrowth/standards/technical_report). We considered children with weight-for-age $z$-scores $<3$ SDs from the median weight-for-age as severely underweight and weight-forheight $\mathrm{z}$-scores $<3$ SDs from the median weight-for-height as severely stunted. We performed analyses using Stata 14.0 (https://www.stata.com/stata14) and considered p values $<0.05$ as the criterion for statistical significance.

\section{Ethics Statement}

Ethics approval for this study was granted by The Gambia Government/Medical Research Council Joint Ethics Committee and the London School of Hygiene and Tropical Medicine Ethics Committee. We obtained written informed consent from the parents or guardians of all patients.

\section{Results}

In total, 33,060 children met the criteria for investigation, and $27,851(84.2 \%)$ blood samples were collected and cultured (Figure 2). Contaminants grew in the cultures of 2,539 (9.1\%) blood samples; these samples were excluded from analysis because contamination can mask an $S$. aureus bacteremia diagnosis.

\section{Bacteremia}

Bacteremia was identified in 1,130 children 0-59 months of age (Table 1). S. aureus was isolated in 198 (17.5\%) 
Figure 2. Flowchart of participants included and excluded in study of Staphylococcus aureus bacteremia incidence in children $<5$ years of age, The Gambia, 2008-2015. Participants were identified through the Basse and Fuladu West Health and Demographic Surveillance Systems. In total, 521 cases were identified through referral surveillance and 418 through admission surveillance.

*Reasons for not having blood culture done included unsuccessful venipuncture ( $\mathrm{n}$ $=487$ ), declined consent for venipuncture $(n=416)$, declined

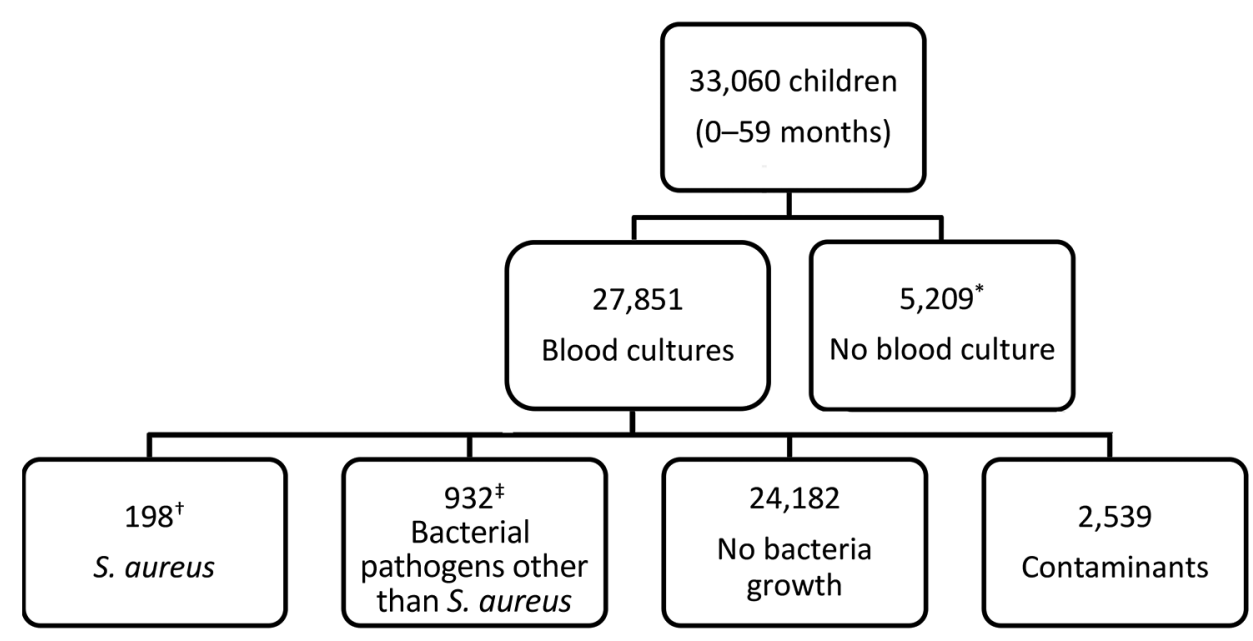
consent to join study $(n=249)$, and unknown $(n=4,057)$. †In total, 76 children were identified through referral surveillance and 122 through admission surveillance. $¥$ Seven patients had polymicrobial bacteremia ( $S$. aureus and a second bacterial pathogen).

children with bacteremia (76 identified through referral surveillance and 122 admission surveillance) and was the most common cause of bacteremia in neonates $(46.4 \%$, 84/181). Pathogens other than S. aureus were isolated from 932 children: S. pneumoniae $(35.0 \%, \mathrm{n}=326)$, Salmonella spp. $(15.1 \%, \mathrm{n}=141)$, and Escherichia spp. $(10.7 \%, \mathrm{n}=$ 100). In 7 children with bacteremia, S. aureus and a second bacterial pathogen were isolated.

\section{Patient Characteristics}

Using the combined admission and referral surveillance data, we found that $18.2 \%(4,541 / 24,885)$ of all patients were severely underweight and $10.9 \%(2,658 / 24,405)$ were severely stunted; $18.3 \%(4,183 / 22,902)$ of patients were admitted in the 2 weeks before disease onset. Antimicrobial drug use in the week before onset of signs and symptoms was uncommon. Most patients had fever $\left(\geq 37.5^{\circ} \mathrm{C}\right)$ and tachypnea (Table 1$)$.

Among patients with $S$. aureus bacteremia, a diagnosis of suspected septicemia was made in $56.2 \%$, suspected pneumonia in $28.4 \%$, and suspected meningitis in $6.7 \%$. The median duration of hospital stay was 5 (interquartile range 2-6) days (Table 1).

Cough and difficult breathing were experienced more often by patients without bacteremia or with bacteremia caused by other pathogens than by patients with $S$. aureus bacteremia (Table 1). S. aureus bacteremia patients were more likely to have a diagnosis of suspected septicemia or other focal sepsis and less likely to have a diagnosis of suspected pneumonia than patients without bacteremia or with bacteremia caused by other pathogens (Table 1).

Incidence and Risk Factors for S. aureus Bacteremia Using the combined referral and admission surveillance data (2011-2015 in BDHSS and 2012-2014 in FWDHSS), we found the incidence of $S$. aureus bacteremia to be 78 (95\% CI 67-91) cases $/ 100,000$ person-years in children $0-59$ months of age. The incidence was highest among neonates $(2,080 \quad[95 \%$ CI $1,621-2,627]$ cases $/ 100,000$ person-years, 3.5 [95\% CI 2.9-4.7] cases/1,000 live births) and decreased in older age groups (Table 2). Incidence of $S$. aureus bacteremia in the 1-11-month age group was 133 (95\% CI 99-174) cases/100,000 person-years, and incidence in the 1-4-year age group was 27 (95\% CI 20-36) cases/100,000 person-years. Among the 84 S. aureus bacteremia cases in neonates, $13(15.5 \%)$ presented in the first week of life and $35(41.7 \%)$ in the second. The incidence of $S$. aureus bacteremia was higher in the wet season than in the dry season (Table 2).

\section{Trends in Incidence of $\boldsymbol{S}$. aureus Bacteremia}

Using referral surveillance data (2008-2015 in BDHSS), we found the mean annual incidence of $S$. aureus bacteremia in children 2-59 months of age to be 22.3 (95\% CI 16.7-29.2) cases $/ 100,000$ person-years. The incidence did not change over this period ( $\mathrm{p}$ value for trend $=0.28$ ), although PCV vaccination coverage increased during this period (Figure 3).

Using the referral surveillance data, we observed that 9 cases (10 cases after enrollment rate adjustment) of $S$. aureus bacteremia occurred in the pre-PCV period and 26 cases (23 cases after enrollment rate adjustment) in the PCV13 period. The crude $S$. aureus bacteremia incidence was 16 cases $/ 100,000$ person-years in the pre-PCV period and 26 cases $/ 100,000$ person-years in the PCV13 period (incidence rate ratio $1.6,95 \%$ CI $0.8-3.5 ; p=0.19$ ). With the increasing size of the population and after adjusting for increased enrollment of eligible children over time, no significant increase in $S$. aureus bacteremia incidence 
Table 2. Factors associated with Staphylococcus aureus bacteremia in children $<5$ years of age identified through 2 surveillance systems, The Gambia, 2011-2015*

\begin{tabular}{|c|c|c|c|c|}
\hline Variable & $\begin{array}{c}\text { No. cases/no. person-years } \\
\text { at risk }\end{array}$ & $\begin{array}{c}\text { Incidence, cases } / 100,000 \\
\text { person-years }\end{array}$ & Incidence rate ratio $(95 \% \mathrm{Cl})$ & $p$ value \\
\hline \multicolumn{5}{|l|}{ Age, mo } \\
\hline $24-59$ & $18 / 128,994$ & 14.0 & 1 & \\
\hline $12-23$ & $29 / 44,433$ & 65.3 & $4.70(2.6-8.4)$ & \\
\hline $1-11$ & $53 / 39,969$ & 132.6 & $9.50(5.6-16.2)$ & \\
\hline$<1$ & $70 / 3,367$ & 2079.0 & $148.99(88.8-250.1)$ & $<0.001$ \\
\hline \multicolumn{5}{|c|}{ (2) } \\
\hline M & $82 / 107,515$ & 76.3 & 1 & \\
\hline $\mathrm{F}$ & $88 / 109,248$ & 80.6 & $1.06(0.8-1.4)$ & 0.72 \\
\hline \multicolumn{5}{|l|}{ Season } \\
\hline Dry & $85 / 144,508$ & 58.8 & 1 & \\
\hline Wet & $85 / 72,255$ & 117.6 & $2.00(1.5-2.7)$ & $<0.001$ \\
\hline
\end{tabular}

were prostration at clinical presentation and musculoskeletal swelling with or without tenderness (Table 3 ).

\section{Treatment and Susceptibility of Isolates}

Among $S$. aureus bacteremia patients identified through referral surveillance, $17.1 \%(13 / 76)$ received initial empiric therapy with cloxacillin, $23.7 \%$ (18/76) ampicillin, $31.6 \%(24 / 76)$ penicillin, and $50.0 \%(38 / 76)$ gentamicin; $50(65.8 \%)$ of these patients received $>1$ antimicrobial drug. The mortality rate did not differ by empiric therapy. Among the 193 S. aureus isolates tested, 3.1\% were methicillin-resistant (Table 4).

\section{Discussion}

We estimated the incidence and CFR of $S$. aureus bacteremia in a rural part of The Gambia using surveillance data over a 5-year period and evaluated trends in incidence over an 8 -year period. The incidence was high, particularly among neonates (3.5 cases/1,000 live births), but did not increase with time (Figure 3). The CFR (14.1\%) was substantial (Table 1).

The observed incidence of $S$. aureus bacteremia in The Gambia among children 0-59 months of age (78.4 cases/100,000 person-years) was higher than that for industrialized countries $(6.5-42.0$ cases/100,000 personyears) $(22,23)$ and some countries of Africa (4) and Asia $(24,25)$, although lower than that reported for Mozambique (12). S. aureus bacteremia incidence was reported to be 27 cases $/ 100,000$ person-years in children $<5$ years in Kenya (4) and 101 cases/100,000 person-years in Mozambique (12). In Thailand, a study that reviewed national hospital-based data on bacteremia reported a $S$. aureus bacteremia incidence of 2.5 cases/100,000 person-years (24), whereas a population-based study in Bangladesh that focused on children 1-59 months of age with respiratory symptoms reported an incidence of 9.9 cases $/ 100,000$ person-years (25). The differences in incidence among studies are likely related to the different selection criteria used in the various studies, nutritional status of the patients, presence of concurrent medical conditions, or high levels of antimicrobial drug use without a prescription, especially in Asia (26).

During 2008-2015, we found no trend in S. aureus bacteremia incidence in The Gambia. Researchers in industrialized countries have shown an increase in the proportion of all bacteremia cases caused by $S$. aureus after the introduction of PCV (27). However, our data do not support an association between $S$. aureus bacteremia incidence and the introduction of PCV. Further studies in different settings could help confirm this finding.

The incidence of $S$. aureus bacteremia was highest in neonates, 8 times that reported in Kenya (4), and $S$. aureus was the most common cause of bacteremia in this age group. This finding is similar to those of other studies conducted in Africa $(12,14)$, where $S$. aureus was responsible for $39.0 \%-56.2 \%$ of isolates recovered from neonates. $S$. aureus carriage, which is likely a prerequisite for disease, is also highest during the neonatal period, higher than the carriage of S. pneumoniae and H. influenzae (28). In addition to high rates of acquisition of $S$. aureus

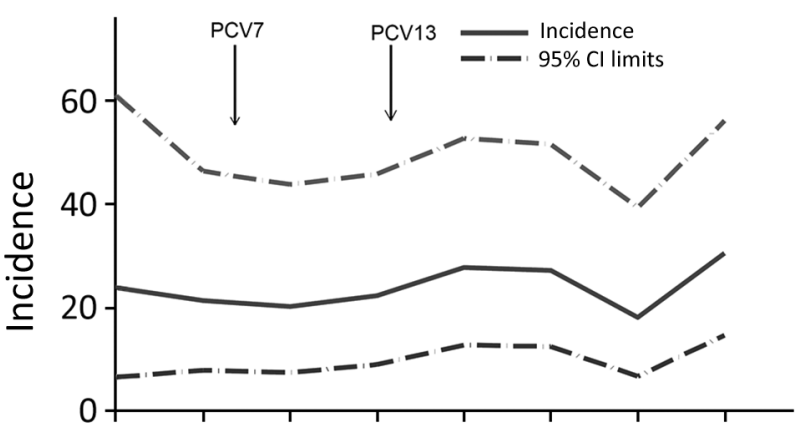

20082009201020112012201320142015

Figure 3. Unadjusted annual incidence of Staphylococcus aureus bacteremia (cases $/ 100,000$ person-years) in children 2-59 months of age, Basse, The Gambia, 2008-2015. Cases were identified by referral surveillance through the Basse Health and Demographic Surveillance System. Arrows indicate introduction of PCV7 and PCV13. PCV7, 7-valent pneumococcal conjugate vaccine; PCV13, 13-valent pneumococcal conjugate vaccine. 
Table 3. Sociodemographic and clinical parameters associated with death from Staphylococcus aureus bacteremia among children $<5$ years of age identified through 2 surveillance systems, The Gambia, 2008-2015*

\begin{tabular}{|c|c|c|c|c|c|}
\hline Parameter & Deaths/persons at risk (\%) & Unadjusted OR (95\% Cl) & $p$ value & Adjusted OR $(95 \% \mathrm{Cl}) \dagger$ & $p$ value \\
\hline \multicolumn{6}{|l|}{ Age, mo } \\
\hline$<1$ & $13 / 84(15.5)$ & Referent & \multicolumn{3}{|c|}{ Referent } \\
\hline $1-11$ & $8 / 61(13.1)$ & $0.8(0.3-2.1)$ & \multicolumn{3}{|c|}{$0.9(0.4-2.6)$} \\
\hline $12-23$ & $4 / 33(12.1)$ & $0.8(0.2-2.5)$ & \multicolumn{3}{|c|}{$1.3(0.4-4.6)$} \\
\hline 24-59 & $3 / 20(15.0)$ & $1.0(0.3-3.8)$ & $0.96 \ddagger$ & $1.1(0.3-4.6)$ & 0.96 \\
\hline \multicolumn{6}{|l|}{ Sex } \\
\hline M & $16 / 97(16.5)$ & Referent & \\
\hline $\mathrm{F}$ & $12 / 101(11.9)$ & $0.7(0.3-1.5)$ & 0.35 & & \\
\hline \multicolumn{6}{|l|}{ Severely stunted§ } \\
\hline No & $20 / 150(13.3)$ & Referent & \\
\hline Yes & $5 / 41(12.2)$ & $0.9(0.3-2.6)$ & 0.85 & & \\
\hline \multicolumn{6}{|l|}{ Axillary temperature } \\
\hline $36.5^{\circ} \mathrm{C}-37.5^{\circ} \mathrm{C}$ & $4 / 18(22.2)$ & Referent & \multirow{3}{*}{\multicolumn{3}{|c|}{0.48}} \\
\hline$<36.5^{\circ} \mathrm{C}$ & $4 / 40(10.0)$ & $0.4(0.1-1.8)$ & & & \\
\hline$>37.5^{\circ} \mathrm{C}$ & $20 / 140(14.3)$ & $0.6(0.2-2.0)$ & & & \\
\hline \multicolumn{6}{|l|}{ Pulse rate, beats/minף } \\
\hline Within reference ranges & $13 / 114(11.4)$ & Referent & \multirow{2}{*}{\multicolumn{3}{|c|}{0.20}} \\
\hline Increased for age & $15 / 84(17.9)$ & $1.7(0.8-3.8)$ & & & \\
\hline \multicolumn{6}{|c|}{ Respiratory rate, breaths/min\# } \\
\hline Within reference ranges & $8 / 70(11.4)$ & Referent & \multirow{2}{*}{\multicolumn{3}{|c|}{0.41}} \\
\hline Increased for age & $20 / 128(15.6)$ & $1.4(0.6-3.5)$ & & & \\
\hline \multicolumn{6}{|c|}{ Need for oxygen supplementation } \\
\hline No & $21 / 165(12.7)$ & Referent & \multirow{2}{*}{\multicolumn{3}{|c|}{022}} \\
\hline Yes & $7 / 33(21.2)$ & $1.9(0.7-4.8)$ & & & \\
\hline \multicolumn{6}{|l|}{ Season } \\
\hline Dry & $18 / 101(17.8)$ & Referent & \multirow{2}{*}{\multicolumn{3}{|c|}{013}} \\
\hline Wet & $10 / 97(10.3)$ & $0.5(0.2-1.2)$ & & & \\
\hline \multicolumn{6}{|l|}{ Cough } \\
\hline No & $13 / 95(13.7)$ & Referent & \multirow{2}{*}{\multicolumn{3}{|c|}{086}} \\
\hline Yes & $15 / 103(14.6)$ & $1.1(0.5-2.4)$ & & & \\
\hline \multicolumn{6}{|l|}{ Difficult breathing } \\
\hline No & $14 / 108(13.0)$ & Referent & \\
\hline Yes & $14 / 89(15.7)$ & $1.3(0.6-2.8)$ & 0.58 & & \\
\hline \multicolumn{6}{|l|}{ Prostration } \\
\hline No & $17 / 168(10.1)$ & Referent & \multirow{2}{*}{\multicolumn{3}{|c|}{ Referent }} \\
\hline Yes & $11 / 29(37.9)$ & $5.4(2.2-13.4)$ & & $5.7(2.2-14.8)$ & 0.01 \\
\hline \multicolumn{6}{|l|}{ Admitted in previous 2 weeks } \\
\hline No & 20/131 (15.3) & Referent & \multirow{2}{*}{\multicolumn{3}{|c|}{0.16}} \\
\hline Yes & $2 / 31(6.5)$ & $0.4(0.1-1.7)$ & & & \\
\hline $\begin{array}{l}\text { *Surveillance data are from the } \\
\text { OR, odds ratio. } \\
\text { †Adjusted for age only. } \\
\text { †p value for trend. } \\
\text { §Defined as weight-for-height } z \\
\text { scores from the } 2006 \text { World He } \\
\text { weight-for-height measurement } \\
\text { TThe reference ranges for pulse } \\
\text { beats/min for children } 1-2 \text { years } \\
\text { beats/min for children } 7-9 \text { years } \\
\# \text { Increased respiratory rate was } \\
\text { min for children }>1-5 \text { years of a }\end{array}$ & $\begin{array}{l}\text { lealth and Demographic Surveilla } \\
3 \text { SDs from median weight-for-he } \\
\text { anization child growth standards } \\
\text { ere } 70-190 \text { beats } / \mathrm{min} \text { for childre } \\
80-120 \text { beats } / \mathrm{min} \text { for children } 3 \\
\text { and } 60-100 \text { beats } / \mathrm{min} \text { for childr } \\
\text { as }>60 \text { breaths } / \mathrm{min} \text { for children }\end{array}$ & $\begin{array}{l}\text { eight for the corresponding age } \\
\text { in Stata } 14.0 \text { (https://www.stat } \\
-4 \text { years of age, } 75-115 \text { beats } \\
\text { en }>10 \text { years of age. } \\
<2 \text { months of age, }>50 \text { breaths }\end{array}$ & $\begin{array}{l}\text { group. We } \\
\text { a.com/stat } \\
\text { ats/min for } \\
\text { min for ch } \\
\text { /min for ch }\end{array}$ & $\begin{array}{l}\text { calculated weight-for-height } \\
\text { 14). Neonates were not inclue } \\
\text { children } 1-11 \text { months of age, } \\
\text { dren 5-6 years of age, } 70-11 \\
\text { dren } 2-12 \text { months of age, }>4\end{array}$ & $\begin{array}{l}\text { System. } \\
\text { sing z- } \\
\text { ed in } \\
80-130 \\
0 \\
\text { breaths/ }\end{array}$ \\
\hline
\end{tabular}

during the neonatal period, other reasons for the high risk for $S$. aureus bacteremia might include an immature immune system (29).

In our study, only $16 \%$ of the $S$. aureus bacteremia cases in neonates presented within the first week of life, unlike for group B Streptococcus disease, where $80 \%$ of parents seek treatment for their neonates within this period (30). Reasons for the difference in timing of treatment might relate to the age at and source of $S$. aureus acquisition.

We found S. aureus bacteremia to be more common during the wet season. This seasonal variation might relate to $S$. aureus colonization (a prerequisite for disease), which is highest during the wet season (31), or seasonal differences in the incidence of viral infections, which are known to disrupt mucosal epithelium, thereby encouraging $S$. aureus invasion (32). In a study of US adults (33), the peak incidence of $S$. aureus infection occurred during the winter months and coincided with the peak incidence of viral infections. In Africa, the incidence of viral infections usually peaks during the wet season (34), coinciding with the peak $S$. aureus bacteremia incidence. 
Table 4. Antimicrobial drug susceptibility of Staphylococcus aureus isolates from children $<5$ years of age identified through 2 surveillance systems, The Gambia, 2008-2015*

\begin{tabular}{lcccc}
\hline Antimicrobial drug & No. isolates tested & No. $(\%)$ sensitive & No. (\%) intermediate & No. (\%) resistant \\
\hline Cefoxitin† & 193 & $187(96.9)$ & 0 & $6(3.1)$ \\
Chloramphenicol & 186 & $176(94.6)$ & $2(1.1)$ & $8(4.3)$ \\
Cotrimoxazole & 180 & $119(66.1)$ & $21(11.7)$ & $40(22.2)$ \\
Erythromycin & 173 & $141(81.5)$ & $24(13.9)$ & $8(4.6)$ \\
Gentamicin & 177 & $174(98.3)$ & 0 & $3(1.7)$ \\
Oxacillin & 194 & $170(87.6)$ & $24(12.4)$ & 0 \\
Tetracycline & 180 & $128(71.1)$ & $2(1.1)$ & $50(27.8)$ \\
\hline
\end{tabular}

*Surveillance data are from the Basse Health and Demographic Surveillance System and the Fuladu West Health and Demographic Surveillance System. †Cefoxitin was used as a surrogate for methicillin-resistant isolates as recommended by the Clinical and Laboratory Standards Institute (21).

The CFR in our study was similar to (10) or greater than that reported by others $(12,23)$. Variation in CFRs could be explained by differences between study populations in terms of age, quality of and access to healthcare, focus of infection, antimicrobial drug resistance rates, severity of $S$. aureus bacteremia, or presence of concurrent medical conditions. In our study, $71.4 \%$ of deaths occurred on the day of admission, which might be a reflection of severity of disease when care was sought. Even though age is strongly associated with $S$. aureus bacteremia-related death $(10,11)$, in our study CFR did not vary with age.

The strengths of our study were that the surveillance was population-based and uninterrupted and that blood culture was performed on $>84 \%$ of eligible patients. However, the study also had some limitations. First, incidence might have been underestimated because some persons with $S$. aureus bacteremia never seek treatment at hospitals and the sensitivity of blood culture is $<100 \%$. Second, an increasing rate of enrollment and investigation over time required adjustment of annual case counts. Third, prior use of antimicrobial drugs, although uncommon in our study area, might have reduced the detection of $S$. aureus bacteremia by blood culture. Last, our study was not specifically designed to evaluate risk factors for $S$. aureus bacteremia. For example, $S$. aureus nasal carriage, hospitalization in the previous 6 months, and HIV status were not systematically assessed.

In conclusion, we demonstrated that the incidence of S. aureus bacteremia is high in rural Gambia, especially in neonates and infants. Strategies are urgently needed to reduce the burden of $S$. aureus bacteremia and should target children in their first month of life.

\section{Acknowledgments}

We thank the staffs of Basse District Hospital (formerly known as Basse Health Centre), Bansang Hospital, and the health facilities in Demba Kunda, Fatoto, Gambissara, Garawol, Koina, Brikama Ba, and Jakhaly. We also thank the staff of the Expanded Programme on Immunisation of The Gambia and the government of The Gambia for their ongoing collaboration with the Medical Research Council Unit The Gambia. We appreciate all staff at the Medical Research Council Unit The Gambia Basse Field Station (especially the staff who worked on the
Pneumococcal Surveillance Project and the BHDSS and FWHDSS) for their support and the residents living in the regions surveilled by the BHDSS and FWHDSS for participating in the study staff. We are particularly grateful to the parents and guardians who allowed their children to participate in this study.

The work was supported by GAVI's Pneumococcal Vaccines Accelerated Development and Introduction Plan (Bloomberg School of Public Health, Johns Hopkins University, Baltimore, MD, USA), the Bill \& Melinda Gates Foundation (OPP 1020372), and the UK Medical Research Council.

\section{About the Author}

Dr. Odutola is a PhD student working at the Medical Research Council Unit The Gambia at the London School of Hygiene and Tropical Medicine, London, UK. Her research interests include epidemiology and $S$. aureus diseases.

\section{References}

1. United Nations Inter-agency Group for Child Mortality Estimation. Levels \& trends in child mortality report 2017. New York: United Nations Children's Fund; 2017.

2. Liu L, Johnson HL, Cousens S, Perin J, Scott S, Lawn JE, et al.; Child Health Epidemiology Reference Group of WHO and UNICEF. Global, regional, and national causes of child mortality: an updated systematic analysis for 2010 with time trends since 2000. Lancet. 2012;379:2151-61. http://dx.doi.org/10.1016/ S0140-6736(12)60560-1

3. Blomberg B, Manji KP, Urassa WK, Tamim BS, Mwakagile DS, Jureen R, et al. Antimicrobial resistance predicts death in Tanzanian children with bloodstream infections: a prospective cohort study. BMC Infect Dis. 2007;7:43. http://dx.doi.org/ 10.1186/1471-2334-7-43

4. Berkley JA, Lowe BS, Mwangi I, Williams T, Bauni E, Mwarumba S, et al. Bacteremia among children admitted to a rural hospital in Kenya. N Engl J Med. 2005;352:39-47. http://dx.doi.org/10.1056/NEJMoa040275

5. Oluwalana C, Howie SR, Secka O, Ideh RC, Ebruke B, Sambou S, et al. Incidence of Haemophilus influenzae type b disease in The Gambia 14 years after introduction of routine Haemophilus influenzae type b conjugate vaccine immunization. J Pediatr. 2013;163(Suppl):S4-7. http://dx.doi.org/10.1016/ j.jpeds.2013.03.023

6. Mackenzie GA, Hill PC, Jeffries DJ, Hossain I, Uchendu U, Ameh D, et al. Effect of the introduction of pneumococcal conjugate vaccination on invasive pneumococcal disease in The Gambia: a population-based surveillance study. Lancet Infect Dis. 2016;16:703-11. http://dx.doi.org/10.1016/S1473-3099(16)00054-2 
7. Waters D, Jawad I, Ahmad A, Lukšić I, Nair H, Zgaga L, et al. Aetiology of community-acquired neonatal sepsis in low and middle income countries. J Glob Health. 2011;1:154-70.

8. Johnson AP, Pearson A, Duckworth G. Surveillance and epidemiology of MRSA bacteraemia in the UK. J Antimicrob Chemother. 2005;56:455-62. http://dx.doi.org/10.1093/jac/dki266

9. Stoll BJ, Hansen NI, Sánchez PJ, Faix RG, Poindexter BB, Van Meurs KP, et al.; Eunice Kennedy Shriver National Institute of Child Health and Human Development Neonatal Research Network. Early onset neonatal sepsis: the burden of group B streptococcal and E. coli disease continues. Pediatrics. 2011;127:817-26. http://dx.doi.org/10.1542/peds.2010-2217

10. Cobos-Carrascosa E, Soler-Palacín P, Nieves Larrosa M, Bartolomé R, Martín-Nalda A, Antoinette Frick M, et al. Staphylococcus aureus bacteremia in Children: changes during eighteen years. Pediatr Infect Dis J. 2015;34:1329-34. http://dx.doi.org/10.1097/INF.0000000000000907

11. Mejer N, Westh H, Schønheyder HC, Jensen AG, Larsen AR, Skov R, et al.; Danish Staphylococcal Bacteraemia Study Group. Stable incidence and continued improvement in short term mortality of Staphylococcus aureus bacteraemia between 1995 and 2008. BMC Infect Dis. 2012;12:260. http://dx.doi.org/ 10.1186/1471-2334-12-260

12. Sigaúque B, Roca A, Mandomando I, Morais L, Quintó L, Sacarlal J, et al. Community-acquired bacteremia among children admitted to a rural hospital in Mozambique. Pediatr Infect Dis J. 2009;28:108-13. http://dx.doi.org/10.1097/INF.0b013e318187a87d

13. Mulholland EK, Ogunlesi OO, Adegbola RA, Weber M, Sam BE, Palmer A, et al. Etiology of serious infections in young Gambian infants. Pediatr Infect Dis J. 1999;18(Suppl):S35-41. http://dx.doi.org/10.1097/00006454-199910001-00007

14. Uzodimma CC, Njokanma F, Ojo O, Falase M, Ojo T. Bacterial isolates from blood cultures of children with suspected sepsis in an urban hospital in Lagos: a prospective study using BACTEC blood culture system. Internet J Pediatr Neonatol. 2013;16:1623.

15. Groome MJ, Albrich WC, Wadula J, Khoosal M, Madhi SA. Community-onset Staphylococcus aureus bacteraemia in hospitalised African children: high incidence in HIV-infected children and high prevalence of multidrug resistance. Paediatr Int Child Health. 2012;32:140-6. http://dx.doi.org/10.1179/146532811 1Y.0000000044

16. Hill PC, Onyeama CO, Ikumapayi UN, Secka O, Ameyaw S, Simmonds N, et al. Bacteraemia in patients admitted to an urban hospital in West Africa. BMC Infect Dis. 2007;7:2. http://dx.doi.org/10.1186/1471-2334-7-2

17. Scott S, Odutola A, Mackenzie G, Fulford T, Afolabi MO, Jallow YL, et al. Coverage and timing of children's vaccination: an evaluation of the expanded programme on immunisation in The Gambia. PLoS One. 2014;9:e107280. http://dx.doi.org/10.1371/ journal.pone. 0107280

18. Mwesigwa J, Okebe J, Affara M, Di Tanna GL, Nwakanma D, Janha $\mathrm{O}$, et al. On-going malaria transmission in The Gambia despite high coverage of control interventions: a nationwide cross-sectional survey. Malar J. 2015;14:314. http://dx.doi.org/ 10.1186/s12936-015-0829-6

19. Mackenzie GA, Plumb ID, Sambou S, Saha D, Uchendu U, Akinsola B, et al. Monitoring the introduction of pneumococcal conjugate vaccines into West Africa: design and implementation of a population-based surveillance system. PLoS Med. 2012;9:e1001161. http://dx.doi.org/10.1371/journal.pmed.1001161

20. Adegbola RA, Falade AG, Sam BE, Aidoo M, Baldeh I, Hazlett D, et al. The etiology of pneumonia in malnourished and wellnourished Gambian children. Pediatr Infect Dis J. 1994;13:975-82. http://dx.doi.org/10.1097/00006454-199411000-00008

21. Clinical and Laboratory Standards Institute. Performance standards for antimicrobial disk susceptibility tests; approved standard - twelfth edition (M02-A12). Wayne (PA): The Institute; 2015.

22. Frederiksen MS, Espersen F, Frimodt-Møller N, Jensen AG, Larsen AR, Pallesen LV, et al. Changing epidemiology of pediatric Staphylococcus aureus bacteremia in Denmark from 1971 through 2000. Pediatr Infect Dis J. 2007;26:398-405. http://dx.doi.org/10.1097/01.inf.0000261112.53035.4c

23. Asgeirsson H, Gudlaugsson O, Kristinsson KG, Vilbergsson GR, Heiddal S, Haraldsson A, et al. Low mortality of Staphylococcus aureus bacteremia in Icelandic children: nationwide study on incidence and outcome. Pediatr Infect Dis J. 2015;34:140-4. http://dx.doi.org/10.1097/INF.0000000000000485

24. Kanoksil M, Jatapai A, Peacock SJ, Limmathurotsakul D. Epidemiology, microbiology and mortality associated with community-acquired bacteremia in northeast Thailand: a multicenter surveillance study. PLoS One. 2013;8:e54714. http://dx.doi.org/10.1371/journal.pone.0054714

25. Arifeen SE, Saha SK, Rahman S, Rahman KM, Rahman SM, Bari S, et al. Invasive pneumococcal disease among children in rural Bangladesh: results from a population-based surveillance. Clin Infect Dis. 2009;48(Suppl 2):S103-13. http://dx.doi.org/10.1086/596543

26. Zellweger RM, Carrique-Mas J, Limmathurotsakul D, Day NPJ, Thwaites GE, Baker S, et al.; Southeast Asia Antimicrobial Resistance Network. A current perspective on antimicrobial resistance in Southeast Asia. J Antimicrob Chemother. 2017; 72:2963-72. http://dx.doi.org/10.1093/jac/dkx260

27. Greenhow TL, Hung YY, Herz A. Bacteremia in Children 3 to 36 months old after introduction of conjugated pneumococcal vaccines. Pediatrics. 2017;139:e20162098. http://dx.doi.org/ 10.1542/peds.2016-2098

28. Peacock SJ, Justice A, Griffiths D, de Silva GD, Kantzanou MN, Crook D, et al. Determinants of acquisition and carriage of Staphylococcus aureus in infancy. J Clin Microbiol. 2003; 41:5718-25. http://dx.doi.org/10.1128/JCM.41.12.5718-5725.2003

29. Power Coombs MR, Kronforst K, Levy O. Neonatal host defense against Staphylococcal infections. Clin Dev Immunol. 2013;2013:826303. http://dx.doi.org/10.1155/2013/826303

30. Trijbels-Smeulders M, de Jonge GA, Pasker-de Jong PC, Gerards LJ, Adriaanse AH, van Lingen RA, et al. Epidemiology of neonatal group B streptococcal disease in the Netherlands before and after introduction of guidelines for prevention. Arch Dis Child Fetal Neonatal Ed. 2007;92:F271-6. http://dx.doi.org/10.1136/ adc. 2005.088799

31. Bojang A, Kendall L, Usuf E, Egere U, Mulwa S, Antonio M, et al. Prevalence and risk factors for Staphylococcus aureus nasopharyngeal carriage during a PCV trial. BMC Infect Dis. 2017;17:588. http://dx.doi.org/10.1186/s12879-017-2685-1

32. Wang X, Zhang N, Glorieux S, Holtappels G, Vaneechoutte M, Krysko O, et al. Herpes simplex virus type 1 infection facilitates invasion of Staphylococcus aureus into the nasal mucosa and nasal polyp tissue. PLoS One. 2012; 7:e39875. http://dx.doi.org/10.1371/ journal.pone. 0039875

33. Lewis SS, Walker VJ, Lee MS, Chen L, Moehring RW, Cox CE, et al. Epidemiology of methicillin-resistant Staphylococcus aureus pneumonia in community hospitals. Infect Control Hosp Epidemiol. 2014;35:1452-7. http://dx.doi.org/10.1086/678594

34. Breiman RF, Cosmas L, Njenga M, Williamson J, Mott JA, Katz MA, et al. Severe acute respiratory infection in children in a densely populated urban slum in Kenya, 2007-2011. BMC Infect Dis. 2015;15:95. http://dx.doi.org/10.1186/s12879-015-0827-x

Address for correspondence: Aderonke Odutola, Medical Research

Council Unit The Gambia at the London School of Hygiene and Tropical Medicine, Disease Control and Elimination Theme, 20 Atlantic Rd,

Fajara, PO Box 273, Banjul, The Gambia; email: ceemee10@yahoo.ca 